\title{
THE EFFECT OF LOCAL APPLICATION OF BISPHOSPHONATES IN OSSEOINTEGRATION OF DENTAL IMPLANT: AN EXPERIMENTAL STUDY
}

\author{
Hisham M. S. El Eryani", Hamdy A. M. Marzook ${ }^{* *}$ and Rehab Rizk Abas El Zehary ${ }^{* * *}$
}

\begin{abstract}
Objectives: Bisphosphonates are reported to enhance osseointegration of dental implant and inhibit osteoclast activity. However, few studies evaluated the effect of local application of bisphosphonate in implant osseointegration.

Purpose: This study was conducted to evaluate the effect of local application of bisphosphonate on osseointegration of dental implant.

Materials and methods: Twenty New Zealand white rabbits with average weight $(2.5 \mathrm{~kg}-4 \mathrm{~kg})$ were included in this study. All rabbits randomly divided into two groups; control group $(n=10$ rabbits) and study group ( $\mathrm{n}=10$ rabbits). The dental implant was inserted in tibia of both groups with addition of bisphosphonate which locally applied in osteocyte socket of study group only. All animals would scarified after 29 days. Histomorphometric and histological analysis were done .
\end{abstract}

Results: Histological evaluation showed an increase in new bone formation and bone implant contact in study group with statistically significant difference (P value 0.001) .

Conclusion: Local application of bisphosphonates enhances osseointegration of dental implant.

KEY WORDS: bisphosphonates; osseointegration; bone healing; dental implant

\section{INTRODUCTION}

In recent decades, the use of titanium endosseous dental implants in the treatment of edentulous or partially edentulo us patients has become an alternative to restore function and esthetics ${ }^{(1)}$.
Postmenopausal osteoporosis is a widespread disease and could have serious consequences on the long-term success of the dental implant treatment ${ }^{(2)}$. Many clinicians and researchers have observed that biomaterial osseointegration (OI) is impaired in osteoporotic subjects $^{(3)}$.

\footnotetext{
* Master Degree of Oral and Maxillofacial Surgery, Faculty of Dentistry, Mansoura University, Egypt. ** Assistant Professor of Oral and Maxillofacial Surgery, Faculty of Dentistry, Mansoura University, Mansoura, Egypt. *** Assistant Professor of Oral Biology Department, Faculty of Dentistry, Mansoura University, Mansoura, Egypt.
} 
The effects of different medications on the OI of dental implants have been investigated in several studies using osteoporotic animal models ${ }^{(4)}$.

Bisphosphonates (BP) are pyrophosphate analogs containing a phosphate-carbon-phosphate bond, which is stable to chemical and enzymatic hydrolysis; they strongly bind to hydroxy appetite(HA) crystals and potently inhibit osteoclast-mediated bone resorption while minimally inhibiting osteoblast activity ${ }^{(5,6)}$.

Bisphosphonates inhibit bone resorption by inactivating the osteoclasts ${ }^{(7)}$. Bone resorption commence in the vicinity of an inserted implant. Bisphosphonate shifts the balance between bone formation and bone resorption during the bone remodeling. This effect is desirable since reducing bone resorption may play an important role for early implant stability ${ }^{(8)}$.

Bisphosphonates may enhance the ability of bone to integrate with the implant, leading to rapid $\mathrm{OI}^{(9)}$. Some studies showed improved bony integration of implants to low-density bone by local release of the bisphosphonate as pamidronate and zaloric $\operatorname{acid}(\mathrm{ZA})$ from surface coatings of implants ${ }^{(10,11)}$.

Based on the above mentioned data, it would be of interest to evaluate the effect of local application of bisphosphonates on the OI of dental implants.

\section{MATERIALS AND METHODS}

\section{Metarials:}

\section{Animals}

Twenty New Zealand white rabbits with average body weight $(2.5 \mathrm{~kg}-4 \mathrm{~kg})$, were used in this study, with a good condition and free access to food were selected. All experimental procedures were performed according to a protocol approved by the ethical committee of Faculty of Dentistry, Mansoura University, Egypt. They were kept in a light-controlled room with a 12:12-h light-dark cycle and $22^{\circ} \mathrm{C}$ temperature. Relative humidity of $65-70 \%$ was kept constant. They were received commercial diet and water.

\section{Methods:}

\section{Surgical procedures:}

Animals were submitted for general anesthesia by intraperitoneal injection of ketamine in a dose of $75 \mathrm{mg} / \mathrm{kg}$ body weight and xylazin in a dose of $25 \mathrm{mg} / \mathrm{kg}$ body weight. ${ }^{(12)}$ After completion of anesthesia skin over the medial side of each tibia was shaved and carefully scrubbed with iodine. In each tibia a $5 \mathrm{~cm}$ in length skin incision by blade number 10 was done located two centimeters below the knee joint. All layers were reflected till reaching the tibial bone. In each animal the right tibia was received pure titanium implant (IHDEDENTAL, Gommiswald, Switzerland) (3.3mm in diameter and $8 \mathrm{~mm}$ in length). The osteotomy site preparation was performed using an implant surgical motor with internal and external irrigation ${ }^{(13)}$. Drilling speed was $1200 \mathrm{rpm}$ in a standardized fashion according to manufacturer instructions. The osteotomy sites were prepared in the following manner ${ }^{(14)}$ :

The study group osteotomy sites were first drilled with a pilot drill $2 \mathrm{~mm}$ in diameter used to drill the pilot site to a depth of $8 \mathrm{~mm}$. This was followed by an intermediate drill $2.5 \mathrm{~mm}$ in diameter and finally by a drill of $2.8 \mathrm{~mm}$ in diameter to prepare the final reception sites for $3.3 \mathrm{~mm}$ screw type implants . After preparation of the osteotomy sites and before fixture installation, each osteotomy site was filled with dose 70mg bisphophonate (Fosamax, Merck Sharp \&Dohme, Italy ) dissolving in $3.5 \mathrm{ml}$ of saline which prepared in a glass cup then take in syringe $10 \mathrm{ml}$ which put in prepared socket ${ }^{(15)}$.

Profuse irrigation with saline was performed during the drilling procedures. The implants were then placed into its final positions (Fig. 1) using the manual ratchet. Copious amount of irrigation was used during screwing the implants to its full depth. 
The sites of implantation were irrigated profusely with normal saline.

The control group osteotomy sites were drilled in the same manner as the study group but fixtures installations were done without prior placement of BP.

The wound was sutured in layers using 2-0 vicryl for the skin. The skin was then scrubbed with iodine after suturing . At the predetermined time interval, animals were euthanized at 29day for postoperative examination.

The block samples were sectioned by a saw altogether removal of bone with dental implant, and were prepared for the subsequent examinations.

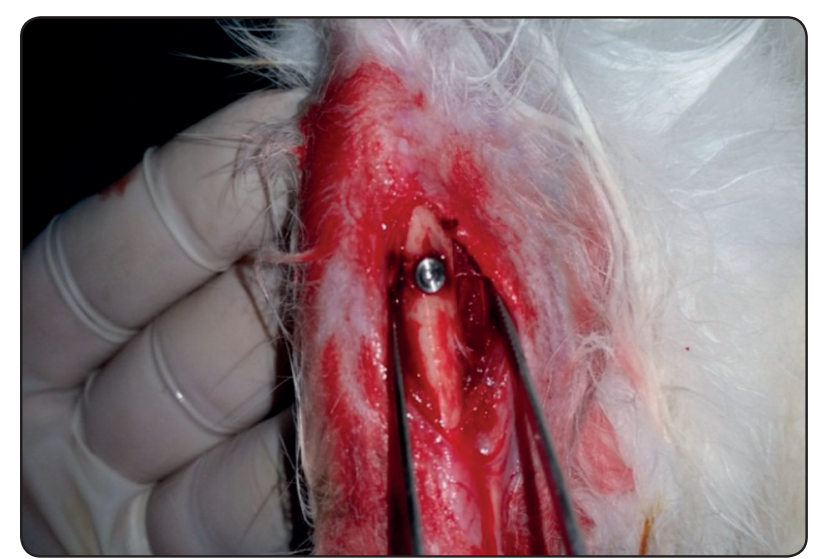

Fig. (1): Implant seated in place on medial aspect of the tibia in study group.

\section{Histological analysis}

\section{1-Conventional histological analysis}

The block samples were put immediately in formal saline as a fixative agent then, it was washed under running water over night to remove the excess of fixative. The specimens 'were placed in 10\% EDTA for decalcification process and the EDTA solution was renewed every day during this process for $3-5$ days. To test for the completion of the decalcification process, the bone was penetrated with sharp instrument (needle), when the sharp instrument entered the surrounding hard structures and the bone simply, the tissue was possibly ready for further treatment. After decalcification, the implant remove from bone by special instrument (implant kit). Tissue dehydration was done by placing it in alcohol between $50 \%$ to $90 \%$. Since paraffin and alcohol are not miscible, the bone tissue was placed in 2 changes of xylene which is miscible with both specimens that became infiltrated with paraffin wax. The xylene after remove specimens of xylene placed in dish of melted, embedding paraffin, and the dish was put in oven with constant temperature about $60^{\circ} \mathrm{C}$ for 2-3 hrs. After cooling of the specimens, by using the micro motor, serial sections were made in the paraffin blocks with the desired thickness of 6 microns. The paraffin ribbon of short length was floated within water bar in about $42^{\circ} \mathrm{C}$. The slide was slip below the paraffin ribbon and elevated from water with the paraffin ribbon. The ready slide(longitudinal section) was placed on a fixed temperature drying table which was regulated to about $37-42^{\circ} \mathrm{C}$, so that the sections adhere to the slide. ${ }^{(16)}$

\section{2- Histochemical analysis}

1- Trichrome stain for detection of collagen fibers

2- Toluidin blue stain for detection of glycosaminoglycans

\section{3- Histomorphometric analysis for trichrome stain computer assisted digital image analysis (digi- tal morphometric analysis.}

Olympus ${ }^{\circledR}$ microscope with $1 / 2 \mathrm{X}$ photo adaptor, using $40 \mathrm{X}$ objective with Olympus ${ }^{\circledR}$ digital camera installed on it were photographed all slide. Intel ${ }^{\circledR}$ core $\mathrm{I} 4{ }^{\circledR}$ based computer using Video Test morphology software with specific built-in routine for stain quantification and area measurement were analyzed result images ${ }^{(17)}$. The mean \%BIC values in the study group were approximately 2 times higher than those in the control group, showing a statistically significant difference $(\mathrm{P}<0.001)$ (Table 1). 


\section{4-Statistical analysis of the data ${ }^{(18)}$.}

Data were tabulated, coded then the computer and analyzed using IBM SPSS software package version $20.0^{(19)}$. Quantitative data were described using range (minimum and maximum), mean, standard deviation and median. Significance of the obtained results was judged at the $5 \%$ level.

\section{RESULTS}

\section{Histological analysis}

\section{1-Haematoxylin and eosin stain $(H \& E)$ for control group}

An appearance of new bone formation around implant surface with regional of bone remodeling. In the majority of samples, there was a little bone trabeculae that mature and irregular originated from old bone and little bone matrix around the implant space. Fig.(2,A)

\section{2-(H\&E) Stain for study group}

In study group, showed new bone formation and more bone trabeculae in the area adjacent to implant surface. Close to implant, showing mature and regular bon trabeculae. Fig. $(2, B)$

\section{Histological analysis}

\section{1- Masson's Trichrome stain for control group}

There was collagen fiber formation and old bone formation around the implant space. Close to implant, showing little bone formation originated from old bone. Fig. $(2, C)$

\section{2-Masson's Trichrome stain for study group}

There were new formed bone trabeculae from old bone around the implant space. Close to implant, showing thick bone trabeculae originated from old bone. Fig. $(2, D)$

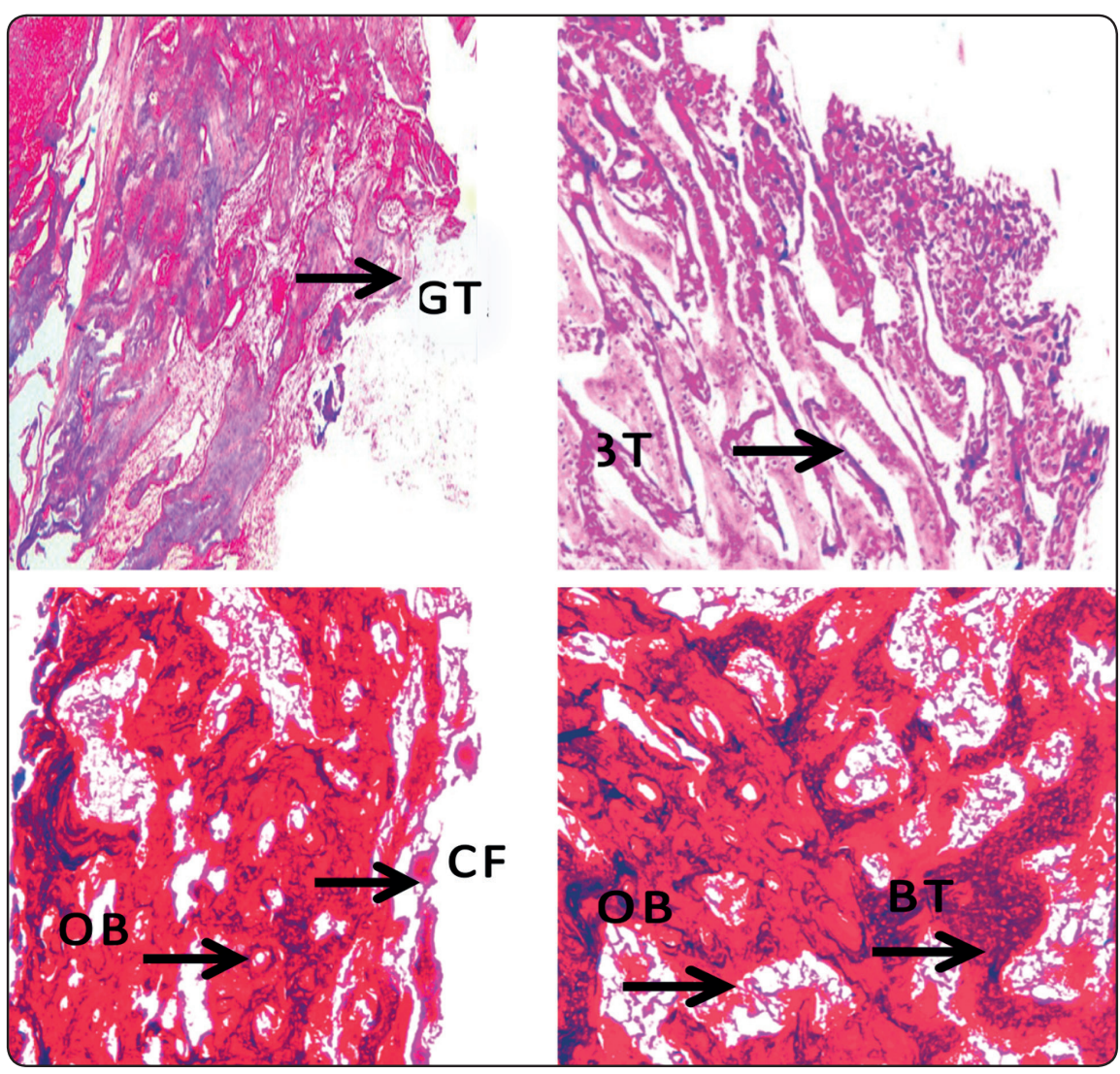

Fig. 2 (A): photomicrograph picture showing granulation tissue(GT) formation around the pure titanium implant in control group. $(\mathrm{H} \& \mathrm{E} \times 100)$ (B): photomicrograph picture showing more bone trabeculae (BT) around the pure titanium implant in study group. $(\mathrm{H} \& \mathrm{E} \times 100)(\mathrm{C})$ : photomicrograph picture showing collagen fibers (CF) and old bone(OB) around implant space in control group. (Masson's trichrome *100) (D): photomicrograph picture showing new formed bone trabeculae (BT) originated of old bone(OB)around implant in study group(Masson's trichrome*100).) 


\section{Digital image analysis}

Digital image analysis of control group showing net collagen matrix of $9.2 \%$ of total area (147060pixel) While in study group showing net collagen matrix of $18.8 \%$ total area (299876pixel).

\section{Statistically analysis}

Comparing the value recorded at 29 days between study group and control group through evaluation Collagen Average Area, there was a statistically significant difference $(\mathrm{P}=0.001)$ (Table 1$)$.

\section{The used tests were}

\section{1 - Student t-test}

For normally quantitative variables, to compare between experimental groups.

TABLE (1) Comparison between experimental groups according to area $\%$ of collagen

\begin{tabular}{|l|c|c|c|c|}
\hline & $\begin{array}{c}\text { Study } \\
(\mathbf{n = 1 0})\end{array}$ & $\begin{array}{c}\text { Control } \\
(\mathbf{n = 1 0})\end{array}$ & $\mathrm{t}$ & $\mathrm{p}$ \\
\hline Area \% & & & & \\
\cline { 1 - 3 } Min. - Max. & $18.89-21.33$ & $9.22-12.98$ & & \\
\cline { 1 - 3 } Mean \pm SD. & $19.99 \pm 0.73$ & $11.40 \pm 1.19$ & \multirow{2}{*}{$19.530^{*}$} & $<0.001^{*}$ \\
\cline { 1 - 3 } Median & 20.01 & 11.34 & & \\
\hline
\end{tabular}

$t, p: t$ and $p$ values for Student t-test for comparing between experimental groups

*: Statistically significant at $\boldsymbol{p} \leq \mathbf{0 . 0 5}$

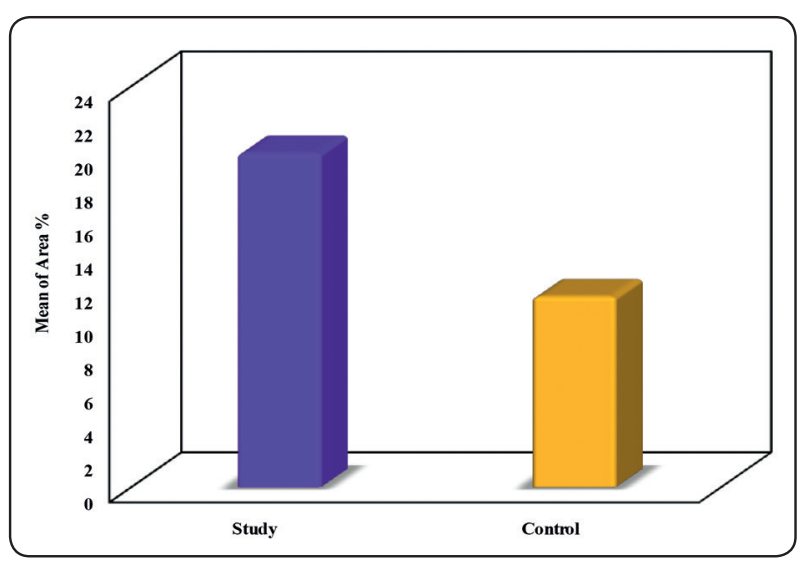

Fig. (3) Comparison between the two groups according to area $\%$ of collagen.

\section{DISCUSSION}

The dental implants are a popular and reliable method for the restoration of missing teeth. Resorption of the edentulous alveolar ridge is a comparatively constant trait after tooth extraction. It is a rapid process during the first 6 months and then develops a progressively, chronic, irreversible, cumulative pattern ${ }^{(20)}$. The specific goal of the current studies was to investigate the influence of local application of bisphosphonate (alendronate sodium) on osseointegration of implants. Locally applied alendronate was able to increase biomechanical fixation and osseointegration of implants inserted in tibia. This increase can be relatively explained by the increases in the amount of bone in contact with and around the implants. Greatest companies of dental implants to increase implant to bone contact, have focused on implant surfaces ${ }^{(21)}$.

This study was conducted in rabbits as the animal model. The design of this study comprised the tibial bone of the rabbit as the implant-host bone bed, the dental implant, and the bisphosphonate. The osteotomy site prepared in two groups with and without bisphosphonates.

This outcome are in agreeing to additional study by Pulikkotil SJ., Nath S., et al. ${ }^{(22)}$ viewing an improvement of osseointegration or decrease implant migration once local application of bisphosphonates. Specially the bisphosphonates (sodium alendronate), similar applied in this experiment, has been exposed to be amongst the greatest powerful of its class ${ }^{(23)}$.

Our results were also in agreeing with the study done by Jakobsen et al. ${ }^{(24)}$ an allograft soaked in a bisphosphonates of different concentration verified the OI of around inserted implants in a hole of $2.5 \mathrm{~mm}$, low concentration of bisphosphonates increase fixation of implant, and also high concentration of bisphosphonates had prevent bone resorption this indicated beneficial effect of this drug. 
Our results were also in accordance with the study done by Stadelmann et al. ${ }^{(25)}$ Established a model for local applied of transporting bisphosphonates around implant, the mechanical stimulation of this medication should be taking into consideration , thus on get expectable outcomes. The authors connected that though the current scientific outcomes are supposed on empirical selections, it's potential to obtain certainty if the kind of bisphosphonates, animal model, and dose approved are taken into thought. There's a understandable accordance between those reportable in the current study and this results that establish in the present literature and those reportable in the current research. There many studies that reportable the local applied of bisphosphonates enhancement in bone density and implant fixation ${ }^{(26,27)}$.

Abtahi J., Tengvall $\mathbf{P}^{(28,29)}$ the use of bisphosphonates may have a positive influence on bone formation and remodeling, and may consequently improve the fixation of titanium implants in humans. This is in agreement with our results revealed a difference in the amount of bone tissue formed in period 29 day in the study than control group.

Amanat et al. ${ }^{(30)}$ found that local application of pamidronate increased the bone mineral content in a model of rat fracture. Before considering the local application of bisphosphonates in clinical practice, the systemic effect of the application should be determined, since little is recognized about the dynamic state of locally-administered bisphosphonates.

A lamellar bone gradually remodeled as result of recent woven bone that rapid formation around implant ${ }^{(31)}$. moreover, the amount of bone increases around implant, it has been presented, with a height density $250 \mu \mathrm{m}$ from the surface of implant ${ }^{(32)}$.

In contrast with our results, when applied bisphosphonates, in some study there didn't enhance the bone around implant integration or perhaps damaged it. Advantage of local Alendronate viewing the fixation of porous-HA-coated implants ${ }^{(33)}$. This influence, additionally shown in alternative studies with Pamidronate ${ }^{(34)}$, Will be because of the mixture bisphosphonates and densely compacted bone ${ }^{(35)}$.

In disagree with our results, Alternative research designs the bisphosphonates that applied locally didn't continually result in significantly improved implant / bone contacts for implants coated with bisphosphonates (36) nor did the extra application of bisphosphonates improve coated implants that appear in its biomechanical properties ${ }^{(37)}$.

Cuairan et al. ${ }^{(38)}$, agreeing to this a study the effect of bisphosphonates when applied locally on dental implant, observed significantly more cortical bone around the implant of control group after 29 days than around implant in which bisphosphonate was applied.

The Histochemical and histomorphometric evaluation in our results by Masson's Trichrome exposed an increasing in the formation of collagen fibers statistically significant by $\mathrm{p}$ value $<0.001$ when compared with control group and more differentiation of osteoblastic cells leading to increase in amount of average area of bone tissue formation in the rabbit treated with local bisphosphonate. This is in agreeing with study done by Manela-Azulay M. et $\mathbf{a l}^{(39)}$, who reported that, the bisphosphonate increase in formatiom of newly bone trabecula and collagen fibers.

The results of the current study was also in agreement with the study done by Yoshinari M., Oda Y. et al ${ }^{(40)}$, and the property of this gel (sodium alendronate) have powerful effect on the inhibition of bone resorption and increase bone formation.

In our results was also in agreement with the study done by Bobyn JD., McKenzie K. et $\mathbf{a l}^{(41)}$. In a study the alendronic acid give large amount of bone adjacent to implant that elution 
was predictable given earlier information of such outcomes using alternative bisphosphonates in additional experimental models.

In our results was also in agreement with the study done by Fleisch et al. ${ }^{(42)}$, bisphosphonates (nonnitrogenated), such as clodronate and etidronate are needed required in very high doses so as to attain inhibition of resorption; really, the equal doses as those that harm physiological mineralization. The expansion of bisphosphonates (nitrogenated), like sodium alendronate, this problem resolved: these are compounds up to ten times additional strong in respect to resorption, but with the great distinction within the prevent of mineralization, and have been presented to be additional sufficient for function like helping with OI.

In our study the influence of local delivery of bisphosphonates on implant OI in rabbit, detected significantly more bone around the implants of the study group after 4 weeks. The study established that the bisphosphonate had a positive influence on formation of bone.

In a contradictory; the study done by Russel et al. ${ }^{(43)}$, the inserted bisphosphonates is predicted to cause restriction or prevent the activity of osteoclast cell. Subsequently activity of the osteoblast cell is closely associated to activity of the osteoclast cell, it is equitable to accept that presence of drug in this conditions may be injured the bone remodelling ${ }^{(43)}$. The worse significantly can describe by obviously changed histomorphological and histomorphometric results establish in the tested group during this study.

During this study, each the analysis of the histomorphometric and histomorphological evaluation presented good results for the group in which the medication interference was done. Though, this was experimental study, within which just single concentration of one type of bisphosphonates (sodium alendronate) was tested, with evaluation completed punctually once twenty eight days in rabbit. this subject remains excellent deal to be explained, essentially with regard to the relevancy in persons, then the clinical situation has seen all the same been discovered in detail in the current scientific literature.

With the method applied for this research and also the evaluation achieved, it was establish that the use of bisphosphonates locally improve implant OI that place in tibia of rabbit. The use of bisphosphonates locally performed to enhance the formation of bone adjacent to implant, in addition the bone remodeling adjacent to implant show positive influence.

These studies support our notion when bisphosphonates applied locally and their affinity for bone may become an important treatment modality to inhibit bone resorption during orthopedic and dental procedures. It seems that the risk of systemic side effects of local delivery of bisphosphonate would be small.

\section{CONCLUSION}

We can conclude that local application of bisphosphonates around dental implant increases bone formation around implant which lead to enhance bone-implant osseointegration.

\section{REFERENCES}

1. Duarte PM., César Neto JB., Gonçalves PF., Sallum EA., Nociti júnior FH. Estrogen deficiency affects bone healing around titanium implants: a histometric study in rats. Implant Dent 2003;12(4):340-6.

2. Cheng L. M. and Gupta V. Teriparatide - Indications beyond osteoporosis. Indian J Endocrinol Metab 2012;16(3): 343 348.

3. Marco F., Milena F., Gianluca G., Vittoria O. Peri-implant osteogenesis in health and osteoporosis. Micron 2005; 36(7-8):630-44.

4. Qi MC., Zhou XQ., Hu J., Du ZJ. Oestrogen replacement therapy promotes bone healing around dental implants in osteoporotic rats. Int J Oral Maxillofac Surg 2004;33(3):279-85. 
5. Peter B., Gauthier O., Laïb S. Local delivery of bisphosphonate from coated orthopedic implants increases implants mechanical stability in osteoporotic rats. J Biomed Mater Res A 2006;76(1):133-43.

6. Fleisch H. Bisphosphonates: mechanisms of action. Endocr Rev 1998;19(1):80-100.

7. Rogers MJ., Gordon S., Benford HL., Coxon FP. Cellular and molecular mechanisms of action of bisphosphonates. Cancer 2000;88(12):2961-78.

8. Skoglund B., Holmertz J., Aspenberg P. Systemic and local ibandronate enhance screw fixation. J Orthop Res 2004;22(5):1108-13.

9. Back DA., Pauly S., Rommel L., Haas NP., Schmidmaier G. Effect of local zoledronate on implant osseointegration in a rat model. BMC Musculoskelet Disord 2012;13:42.

10. Viera-Negrón YE., Ruan W., Winger JN., Hou X., Sharawy MM., Borke JL. Effect of ovariectomy and alendronate on implant osseointegration in rat maxillary bone. J Oral Implantol 2008;34(2):76-82.

11. Peter B., Pioletti DP., Laïb S., Bujoli B., Pilet P., Janvier P. Calcium phosphate drug delivery system: influence of local zoledronate release on bone implant osteointegration. Bone 2005;36(1):52-60.

12. Joerg H. Holstein., ABCDEFG., Julia Schmalenbach., ABCDEFG., Herrmann M., ABCDEFG., et al. Excess dietary methionine does not affect fracture healing in mice 2012;18(12): 469-474.

13. Guimarães MB., Bueno RS., Blaya MBG., Shinkai RSA., Marques LMH. Influence of the local application of sodium alendronate gel on osseointegration of titanium implants. Int J Oral Maxillofac Surg 2015;44(11):1423-9.

14. Eberhardt C., Habermann B., Müller S., Schwarz M., Bauss F., Kurth AHA. The bisphosphonate ibandronate accelerates osseointegration of hydroxyapatite-coated cementless implants in an animal model. J Orthop Sci 2007;12(1):61-6.

15. Omi H., Kusumi T., Kijima H., Toh S. Locally administered low-dose alendronate increases bone mineral density during distraction osteogenesis in a rabbit model. J Bone Joint Surg Br 2007;89(7):984-8.

16. Rentsch C., Schneiders W., Manthey S., Rentsch B. Comprehensive histological evaluation of bone implants 2014;4: 27993.
17. Almahrog J A., Radwan R.S. L., El-Zehery R. R., Mourad I. M. and Grawish E. M. In vivo association of immunophenotyped macrophages expressing CD163 with PDGF-B in gingival overgrowth-induced by three different categories of medications 2016;6(1): 10-17.

18. Kotz S., Balakrishnan N., Read CB., Vidakovic B. Encyclopedia of statistical sciences. Wiley-Interscience; 2006.

19. Lee A. and feeney C.k.b. A smpile giude to IMP SPSS:for version 22.0 2006;89:2.

20. Pal S. U., Dhiman K.N., Singh G., Singh K. R., Mohammad S. Evaluation of implants placed immediately or delayed into extraction sites $2011 ; 2(1)$ : 54-62.

21. Albrektsson T., Wennerberg A. Oral implant surfaces: Part 2--review focusing on clinical knowledge of different surfaces. Int J Prosthodont 2004;17(5):544-64.

22. Pulikkotil SJ., Nath S. Letter to the Editor: re: $1 \%$ alendronate gel as local drug delivery in the treatment of class II furcation defects: a randomized controlled clinical trial. J Periodontol 2014;85(11):1478-9.

23. Gao Y., Zou S., Liu X., Bao C., Hu J. The effect of surface immobilized bisphosphonates on the fixation of hydroxyapatite-coated titanium implants in ovariectomized rats. Biomaterials 2009;30(9):1790-6.

24. Jakobsen T., Baas J., Bechtold JE., Elmengaard B., Søballe $\mathrm{K}$. The effect of soaking allograft in bisphosphonate: a pilot dose-response study. Clin Orthop Relat Res 2010;468(3):867-74.

25. Stadelmann VA., Terrier A., Gauthier O., Bouler J-M., Pioletti DP. Prediction of bone density around orthopedic implants delivering bisphosphonate. J Biomech 2009; 42(9):1206-11.

26. Harmankaya N., Karlsson J., Palmquist A., Halvarsson M., Igawa K., Andersson M., et al. Raloxifene and alendronate containing thin mesoporous titanium oxide films improve implant fixation to bone. Acta Biomater 2013;9(6): 7064-73.

27. Bobyn JD., Thompson R., Lim L., Pura JA., Bobyn K., Tanzer M. Local alendronic acid elution increases net periimplant bone formation: a micro-CT analysis. Clin Orthop Relat Res 2014;472(2):687-94.

28. Abtahi J., Tengvall P., Aspenberg P. Bisphosphonate coating might improve fixation of dental implants in the maxilla: a pilot study. Int J Oral Maxillofac Surg 2010;39(7):673-7. 
29. Abtahi J., Tengvall P., Aspenberg P. A bisphosphonatecoating improves the fixation of metal implants in human bone. A randomized trial of dental implants. Bone 2012;50(5):1148-51.

30. Amanat N., Brown R., Bilston LE., Little DG. A single systemic dose of pamidronate improves bone mineral content and accelerates restoration of strength in a rat model of fracture repair. J Orthop Res 2005;23(5): 1029-34.

31. Bobyn JD., McKenzie K., Karabasz D., Krygier JJ., Tanzer M. Locally delivered bisphosphonate for enhancement of bone formation and implant fixation. J Bone Joint Surg Am 2009;91:23-31.

32. Wermelin K., Suska F., Tengvall P., Thomsen P., Aspenberg P. Stainless steel screws coated with bisphosphonates gave stronger fixation and more surrounding bone. Histomorphometry in rats. Bone 2008;42(2):365-71.

33. Jakobsen T., Kold S., Bechtold JE., Elmengaard B., Søballe K. Local alendronate increases fixation of implants inserted with bone compaction: 12-week canine study. J Orthop Res 2007;25(4):432-41.

34. Tokugawa Y., Shirota T., Ohno K., Yamaguchi A. Effects of bisphosphonate on bone reaction after placement of titanium implants in tibiae of ovariectomized rats. Int $\mathrm{J}$ Oral Maxillofac Implants 2003;18(1):66-74.

35. Agholme F., Aspenberg P. Experimental results of combining bisphosphonates with allograft in a rat model. J Bone Joint Surg Br 2009;91(5):670-5.

36. Langhoff JD., Voelter K., Scharnweber D., Schnabelrauch M., Schlottig F., Hefti T., et al. Comparison of chemically and pharmaceutically modified titanium and zirconia implant surfaces in dentistry: a study in sheep. Int J Oral Maxillofac Surg 2008;37(12):1125-32.

37. Ferguson S.J., Langhoff J.D., Voelter K., von Rechenberg B., Scharnweber D., Bierbaum S., et al. Biomechanical comparison of different surface modifications for dental implants. Int J Oral Maxillofac Implants 2010;23(6): $1037-46$.

38. Cuairán C., Campbell P.M., Kontogiorgos E., Taylor R.W., Melo A.C B.P. Local application of zoledronate enhances miniscrew implant stability in dogs. Am J Orthod Dentofac Orthop 2014;145(6):737-49.

39. Park R., Kim J., Choi H., Park Y., Jung H., Moon P. H. Effect of alendronate on bone remodeling around implant in the rat 2013:5(4): 374-381.

40. Reddy G.T., Kumar T.M V. Formulation and evaluation of Alendronate Sodium gel for the treatment of bone resorptive lesions in Periodontitis. Drug Deliv 2005;12(4):217-22.

41. Yoshinari M., Oda Y., Inoue T., Matsuzaka K., Shimono M. Bone response to calcium phosphate-coated and bisphosphonate-immobilized titanium implants. Biomaterials 2002;23(14):2879-85.

42. Fleisch H. Development of bisphosphonates. Breast Cancer Res 2002;4(1):30-4.

43. Russell RGG., Watts NB., Ebetino FH., Rogers MJ. Mechanisms of action of bisphosphonates: similarities and differences and their potential influence on clinical efficacy. Osteoporos Int 2008;19(6):733-59. 